\title{
CAE Simulator as a Tool for Mechanical and Temperature Analysis in Common Glasses
}

\author{
Cristiano Correa Ferreira1, Everton de Almeida Lucas² \\ ${ }^{1}$ Federal University of Pampa (PPEng / UNIPAMPA), Bagé, RS, Brazil \\ ${ }^{2}$ Federal University of Pampa (UNIPAMPA), Bagé, RS, Brazil
}

\begin{abstract}
This study aimed to analyze the behavior of glass material to mechanical tests in CAE platform of Add-in toolbar of Simulation of Solidworks software. The method used was based on an evaluation of the behavior of glass of different thicknesses and sizes to static testing simulation using the Finite Element Method (FEM). The experiments considered the tension, deformation, and reaction force under the influence of applied loads, as well as the analysis of thermal stress due to different temperatures in glass sheets. Results from analysis presented in the simulator have shown that it is possible to test the mechanical behavior of glass.
\end{abstract}

Keywords: - Glass, mechanical tests, simulation, solidworks, temperature

\section{INTRODUCTION}

Currently, there is a constant search for improving the product quality testing concepts and performance through the use of computational tools. Studies such as [1] have shown that companies are increasingly searching for new technologies through graphic software (CAD) and simulation (CAE) to cut costs while adding quality and better performance in productions. For [2] the successful uses of CAD and CAE software exhibited that the designer can work on developing a product before its conception and improve the project at a low-cost. $[3,4]$ as well as [1] define that CAE software executes a substantial amount of calculations in a downsized time. [4] Demonstrates that this software allows prototypes or scale models for laboratorial testing to be constructed, where instruments placed in strategic locations would collect data of stress, strains, speed, etc.

According to [5], most glass applications today come in the form of panels. [6] States that glass is characterized for being a brittle material, but not weak. Having resistance to breakage, it is not considered a tough material, which is why it is not suitable for applications subject to impact. Given the abovementioned, this paper aims to analyze the virtual behavior of glass in a CAE platform of the add-in toolbar from Solidworks Simulation Software (version 2010).

\section{MATERIALS AND METHODS}

\subsection{Material definition and geometrical characterization}

Initially, an interview was conducted at a company that provides glasses in Bagé, Rio Grande do Sul Brazil. The company works with several brands of glasses and provides products such as doors, windows, bathroom stalls, storefronts and ornaments for a population of around 120.000 inhabitants. With the responses obtained in the interview we decided that common types of glasses with various dimensional parameters used in windows and storefront windows with thickness varying between 3 to $6 \mathrm{~mm}$ would be analyzed. Table 1 shows the dimensional breakdown and thickness of the glasses analyzed. This Table 1 presents two categories of panels used in windows (A) and storefront windows (B), where each category is sorted by a code that is represented by a letter followed by a number.

Table 1 - Data on the glasses investigated in windows (A) and storefront windows (B) in terms of dimension, area, and thickness.

\begin{tabular}{|c|c|c|c|}
\hline Code & Dimension $(\mathrm{mm})$ & Area $\left(\mathrm{mm}^{2}\right)$ & Thickness $(\mathrm{mm})$ \\
\hline A1 & $300 \times 300$ & 90.000 & 3 \\
\hline A2 & $400 \times 300$ & 120.000 & 4 \\
\hline A3 & $800 \times 1.000$ & 800.000 & 3 \\
\hline A4 & $1.000 \times 1.000$ & 1.000 .000 & 4 \\
\hline A5 & $1.000 \times 1.200$ & 1.200 .000 & 3 \\
\hline A6 & $1.500 \times 1.500$ & 2.250 .000 & 4 \\
\hline B1 & $1.500 \times 1.600$ & 2.400 .000 & 5 \\
\hline B2 & $1.500 \times 2.200$ & 3.300 .000 & 6 \\
\hline B3 & $1.900 \times 2.500$ & 4.750 .000 & 5 \\
\hline B4 & $2.500 \times 2.000$ & 5.000 .000 & 6 \\
\hline
\end{tabular}


After the analysis, we reproduced the panels with dimensions and thickness shown in Table 1 in the CAD environment of the graphic software Solidworks 2010. The following items (2.2 and 2.3) describe how the tests were carried out at the CAE platform.

\subsection{Tension tests in relations to the applied load}

The next step of the study comprehends the simulation tests, which were done by applying loads on the panels in the central part, as if they were hit by an impact. The first step in relation to this region was to limit the area on the panel, where the load would be imposed. Therefore, it was necessary to open the drawing of the panel created in the software, select the frontal plane, click on the menu, and choose "Outline" and then "Circle". This was positioned at the center of the major face of the panel having a size of $15 \mathrm{~cm}$ in diameter. This diameter served as reference for the appliance of the load. After this procedure, it was possible to start the simulation test in the edition area called "Add-in of Solidworks Simulation".

To begin the test, we opened the "Add-in" menu of Solidworks Simulation. The activation was achieved through the following steps: open the "Tool" menu; click the "Add-in" toolbar. This automatically opens a dialog box entitled "Activate Add-in". Inside this box, select the "Add-in Solidworks Simulation", selecting both icons located on the right and left columns. From this moment on, it is possible to provide the conditions for the realization of the simulation study. It begins with setting a test over the studied item. Static charges and voltage offset are gradually applied until their total magnitude. Static study was chosen because the tension and displacement loads are applied gradually until they reach their total magnitude. After reaching their total magnitude, the loads remain constant. With this, the relationship between the loads and responses are linear. Furthermore, the linear static analysis allows the calculation of displacements, strains, stresses, and reaction forces under the influence of the applied loads. After choosing the correct type of study, a menu "Simulation" was opened and edited option by option in order to make the computer simulation.

The first menu option provides information such as "editing of the study", as shown in Figure 1a, which allows post-editing after it is ran. The menu "editing of parts" allows one to report on the composition of the material (Fig.1b) of the panel in which the simulation is performed. The menu "connections" is used to edit the connection between two or more parts. The menu "fixture" (Fig.1c) informs us of the location of the part that is restricted to movements. Further, the menu "external loads" (Fig.1d) informs us of the magnitude of the force that is applied on the part. Lastly, the menu "mesh" (Fig.1e) allows the part to be divided into finite element (FEA) for behavioral analysis, after undergoing a certain amount of force, pressure, etc.

In relation to our proposed study, we selected the option "part" and applied "glass" for the type of material. Using this material, we decided to set up a new type of glass and put up the same properties of the glass supplied by the studied company. It should be noted that the data we collected were from the company's catalog found on its website.

In the next editing option called "connections", we chose for it to be "off" because it is not considered a set. In the option "fixtures", the regions of the panel which should be fixed during the application of the loads were indicated; in this case the edges were selected and the fixed geometry was used.

In the option "external loads", we indicated the part of the panel where the load should be applied. After clicking "external loads" and selecting the option "load" a dialog box opens automatically, in which the value of the load to needs to be applied in the menu "load/torque". In this case, we selected the value of the load to be applied be whose magnitude varied from one panel to the other.

Using the same menu, we applied the "symbol settings" option followed by activating "show preview", this serves as an aid which indicates where the distributed force was applied. After that, we went to the top of the menu and clicked on "split", which automatically refers to the menu "selection". In the option "project sketch", we clicked on the circle found in the center of the panel. Then, the tab "other faces to split" appears, and we clicked on the frontal face that contains the circle to activate this split. Afterwards, we clocked on "single direction" and later "create split". A new folder is automatically created in the project file called, "split line". "Split Line" is a restricted area of the frontal face of the panel to which the force was applied. To complete this operation, we needed to confirm, what ends the process of choosing the force magnitude and application in the desired area.

This split was important to run the simulation because it allows one to select an area of $15 \mathrm{~cm}$ of diameter in the panel in relation to the central part. In the end, mesh was added to the part, by selecting the option "create mesh" and a dialog box was automatically opened, entitled "mesh", where a subtitled box called "mesh density" appeared with the options of thick, medium, and thin. In relation to the case under study, we chose to develop a thin mesh, i.e., the part was split into finite elements (divisions) where an average of 65.890 nodes was found in all the parts analyzed. We chose then the option "study" to run the simulation of stress and displacement. Fig.1a presents the screen of the simulation environment, Fig. 1b shows the choice of material, Fig.1c shows the access to the fixture tool, Fig.1d refers to the external loads, Fig.1e shows the mesh, and Fig.1f shows the result of the stress test. 


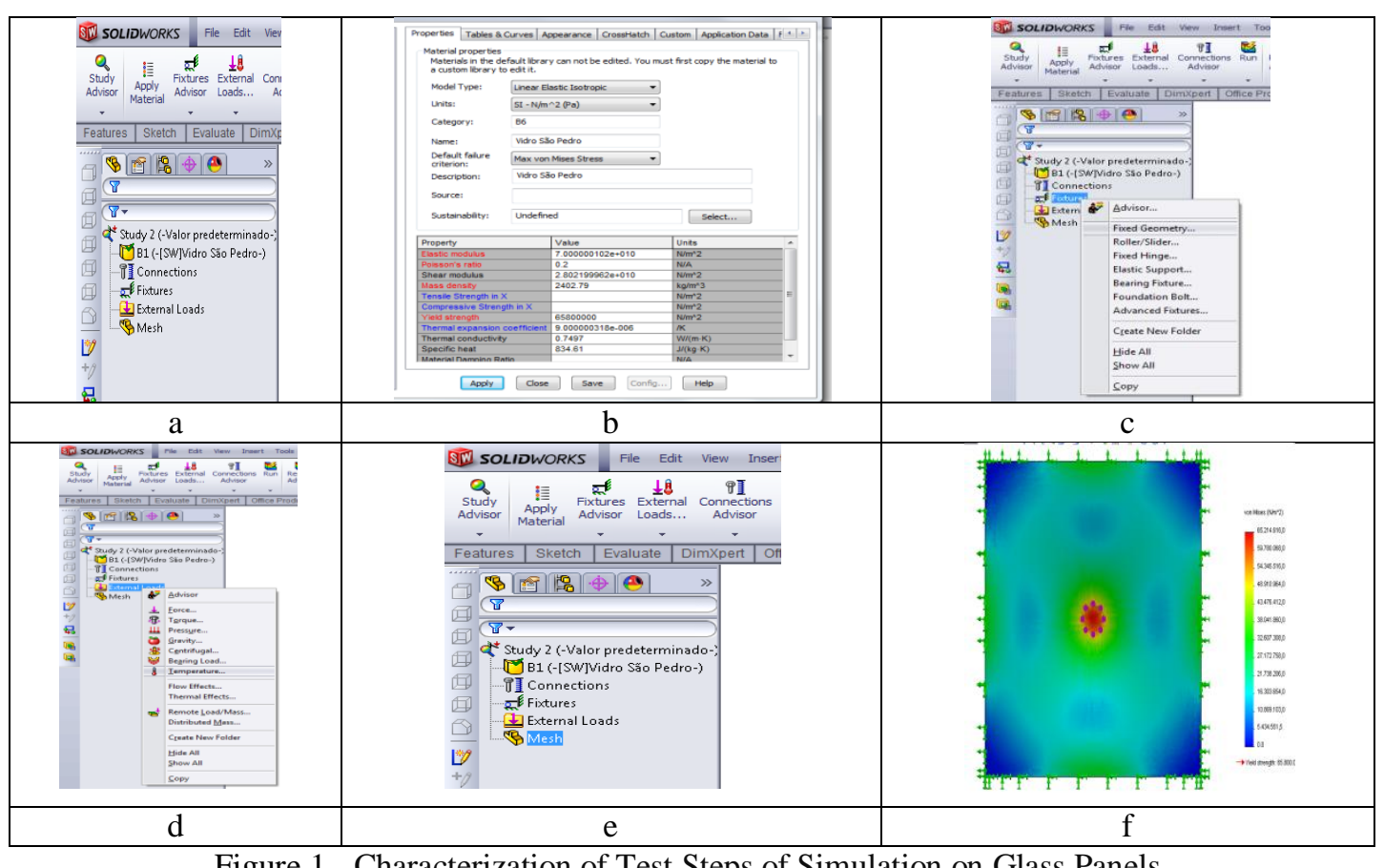

Figure 1 - Characterization of Test Steps of Simulation on Glass Panels.

To define the modulus of rupture, a calculation of the average of all samples tested in laboratory was performed. We adopted the yield strength and calculated the average density of the specimens in order to replace the features of the properties provided by the manufacturer.

With this, we obtained the rupture modulus of this material with a value of $65.8 \times 10^{6} \mathrm{~N} / \mathrm{m}^{2}$, which, consequently, also became the value of yield strength. In regard to glass density, the resulting value obtained was $2.402 .79 \mathrm{~kg} / \mathrm{m}^{3}$. The other properties that were used as parameters for the study were acquired with the manufacturer. Among these properties, we can cite The Elasticity Modulus with value of $7 \times 10^{10} \mathrm{~Pa}$, Poisson's Ratio with a value of 0.2, Shear Modulus with value of $2.8022 \times 10^{10} \mathrm{~N} / \mathrm{m}^{2}$, Coefficient of Thermal Expansion of $9 \times 10^{-6} \mathrm{~m}^{3} / \mathrm{k}$, Thermal Conductivity of $0.7497 \mathrm{~W} /(\mathrm{m} . \mathrm{K})$, and Specific Heat of $834.61 \mathrm{~J} /(\mathrm{kg} . \mathrm{K})$.

\subsection{Stress testing related to the applied temperature}

Upon completion and definition of the simulation of the possible impacts on the glass panels, the climatic factors were taken into account, considering that panels used for windows and storefront windows are usually exposed to climate changes, being directly affected by the variation of temperature throughout the year. The simulation of the influence of temperature was performed in the tool "Simulation (CAE) static study", and the load applied this time was temperature. Climatic factors demonstrated to be relevant in this study, since the city of Bagé-RS presents a climate with significance changes in terms of temperature throughout the year.

According to [7] and [8], Bagé is located in a warm temperate zone of CFA classification within Köppen-Geiger climate classification. The average temperature according to the National Institute of Meteorology for the coldest month (June) is $12.5^{\circ} \mathrm{C}$ and the hottest month (January) is $24^{\circ} \mathrm{C}$. As for the extreme temperatures, the coldest month (July) has an average temperature of $-4^{\circ} \mathrm{C}$ and $41{ }^{\circ} \mathrm{C}$ for the hottest month (January). The analysis factors in terms of temperature took into consideration the above-described five temperatures. Next, we show the steps taken in the "Simulation Add-in" of Solidworks Software to define the thermal stress on the panels, where one must activate the add-in Solidworks Simulation. After that, one clicks on "simulation" and then on "study". Next, "static study" should be clicked on. The, we confirmed the operation by clicking "ok". Automatically after this procedure, a menu composed of six items is opened with the same options of load application from the previous process presented in section 2.2. Compared to the previous simulation, the difference to the temperature application is found in the "External Loads" icon. Added by right clicking and selecting "Temperature", a menu opens and "Select All Exposed Faces" is chosen. After selecting this option, we determined that all the faces of the panel are subject to temperature exposure. From the same menu, the option "Temperature" is selected using Celsius as the unit system in this study. The, one selects the desired temperature. This procedure must be repeated for each panel and for each of the different temperatures defined above.

In order to obtain the result of this simulation, firstly one needs to properly insert the material of the panels, the type of geometry in the study (fixed geometry), and the external loads (which in this case are the 
temperatures) to create the mesh in the part. Then, we gathered the results by right clicking on "Study" and selecting "Run".

\section{RESULTS}

For the simulation of load applications, the results can be observed in Table 2, where the panels of glass used for windows are represented by the letter " $\mathrm{A}$ " and the storefront windows are represented by the letter "B". Each panel has its respective load due to its size and, thereof, each panel is subjected to a different load until the breaking down, according to data contained in the column load (N). Also, the dimensions and thickness of each panel are presented in the units of millimeters $(\mathrm{mm})$ and the area in square millimeters $\left(\mathrm{mm}^{2}\right)$.

Results in Table 2 show that the highest rupture load was obtained in the panels used for storefronts more specifically in B2 of $6 \mathrm{~mm}$ thick and rupture of $2700 \mathrm{~N}$. On the other hand, the lowest breaking load was observed in the window $\mathrm{A} 3$ of $3 \mathrm{~mm}$ thick and with rupture of $700 \mathrm{~N}$.

In the same Table, it is possible to observe the values of maximum stress found in each panel. For these maximum stresses, we can observe that the values presented small variations from one panel to another, a fact that may be explained due to the properties used for glass. As the type of glass used in the simulations was the same for the panels used in windows and storefronts, they presented a similar behavior. In this context, [9] highlight the importance to include the properties of the material in study as well as the information presented by [10], who note that the inclusion of physical properties in combination with computer simulations makes the study closest to real situations. It should be noted that the modulus of rupture was used as yield strength in the physical properties of glass because when the glass breaks, it reaches its strength limit.

The images of the tests in Solidworks Simulation of stress and displacement can be observed in Table 2. For stress, the distribution of the highest intensities are concentrated in the center of the panel and, in some cases, this stress is also found in the its edges, for instance panels A1, A2, A3, A4, A5, A6, B1 and B3. This occurs because both the fixture, which has the property of fixing the panel, and the site of application of the load directly influence the location of the highest stress, thus exalting the importance to refine data in key regions for the study, as reported by [11]. It is also possible to notice from the images on Table 2 that there is a significant concentration of tension in panels such as A1 and A2. This occurs because these two panels have areas significantly smaller when compared to the others, i.e. the smaller the area of the panel, the greater the stress concentration at its edges when undergoing application of loads in a central region.

Regarding images relating to the displacement, it is noticed a radial uniformity, and the cause is related to glass behavior before the application of loads. This behavior is explained by the fact that the glass presents a slight deformation when subjected to external loads and also because the offset was concentrated in the region of load application not being expanded to the rest of the panel. This way, we can characterize the main mechanical property of the glass, which is to be a non-tenacious material that lacks a plastic deformation thus making it difficult to view this deformation. Table 2 also reports that all glasses broke upon application of loads. Table 2 shows the characteristics of the test results involving the application of load in the glasses studied.

\begin{tabular}{|c|c|c|c|c|c|c|c|}
\hline Code & $\begin{array}{l}\text { Force } \\
(\mathbb{N})\end{array}$ & $\begin{array}{c}\text { Dimension } \\
(\mathrm{mm})\end{array}$ & $\begin{array}{l}\text { Thick } \\
\text { ness } \\
(\mathrm{mm})\end{array}$ & $\begin{array}{l}\text { Stress max. } \\
\left(\mathrm{N} / \mathrm{m}^{2} \times 0^{6}\right)\end{array}$ & Rupture & $\begin{array}{l}\text { Stress } \\
\text { image }\end{array}$ & \begin{tabular}{|l} 
Displacem \\
ent \\
image
\end{tabular} \\
\hline A.1 & 1.100 & $300 \times 300$ & 3 & 66.32 & YES & & \\
\hline A.2 & 1.550 & $400 \times 300$ & 4 & 66.35 & YES & & \\
\hline A.3 & 700 & $800 \times 1.000$ & 3 & 66.09 & YES & & \\
\hline A.4 & 1.120 & $1.000 \times 1.000$ & 4 & 65.89 & YES & & \\
\hline A.5 & 720 & $1.000 \times 1.200$ & 3 & 68.04 & YES & & \\
\hline A6 & 1.080 & $1.500 \times 1.500$ & 4 & 66.21 & YES & & \\
\hline B1 & 1.480 & $1.500 \times 1.600$ & 5 & 66.53 & YES & & \\
\hline B2 & 2.700 & $1.500 \times 2.200$ & 6 & 66.09 & YES & & \\
\hline B3 & 1.450 & $1.900 \times 2.500$ & 5 & 66.70 & YES & & \\
\hline B4 & 2.000 & $2.500 \times 2.000$ & 6 & 65.93 & YES & & \\
\hline
\end{tabular}


The graphs of Fig. 2 show the relationship between load and stress in function of the area of each panel, being that each thickness is specifically analyzed.

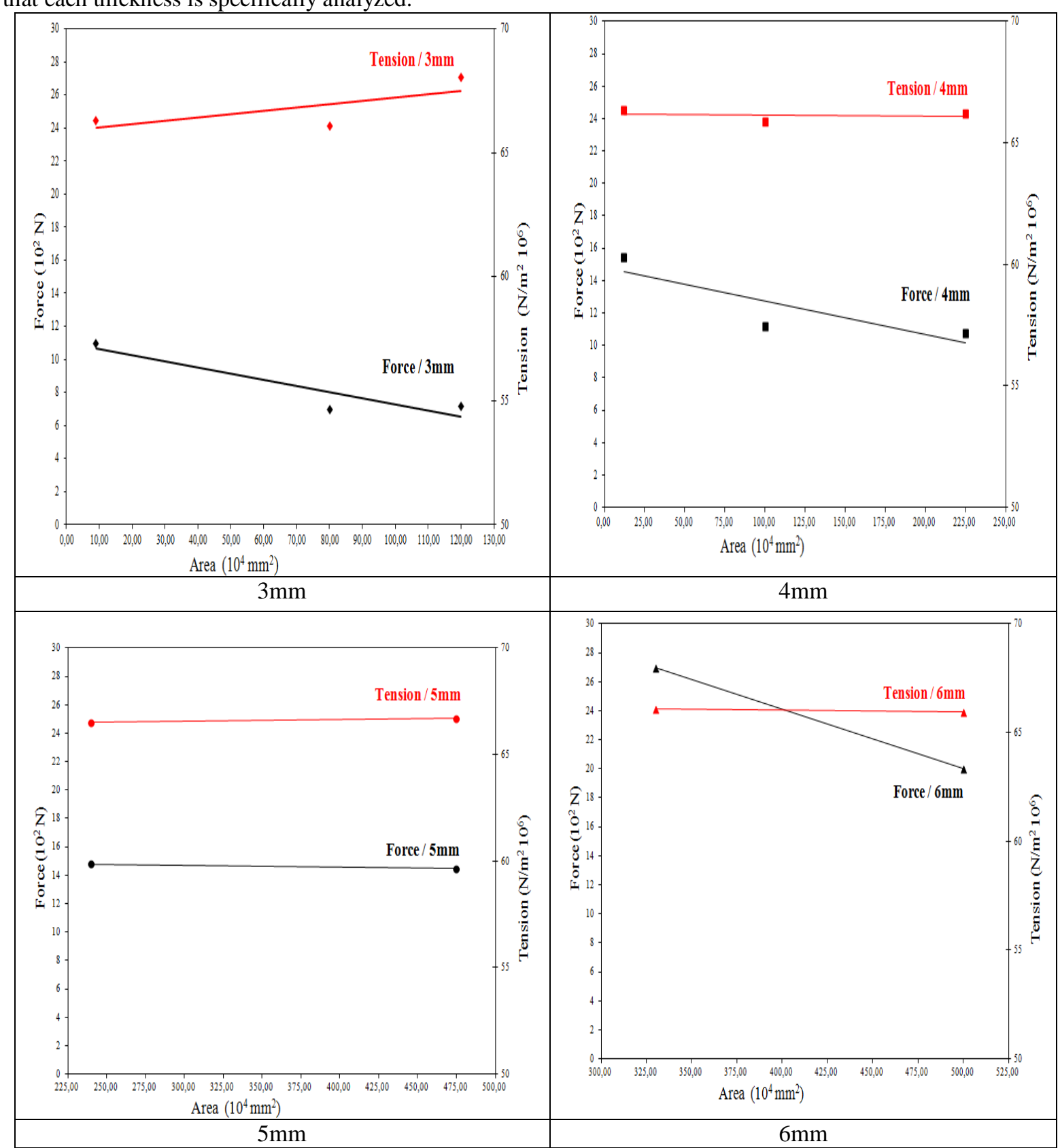

Figure 2 - Load and stress relation in function of area and respective thickness.

For the $3 \mathrm{~mm}$ thick glasses, we observed that the larger the area, the smaller the load applied. On the other hand, the larger the area, the higher is the stress. For $4 \mathrm{~mm}$ thick glasses, the load behavior was similar to those of $3 \mathrm{~mm}$, whereas for stress, it remained constant regardless of the area, showing a strong influence of thickness on this result. Glasses of $5 \mathrm{~mm}$ showed no significant variation in relation to load and stress, which shows that the area has no influence on the behavior of these glasses but the thickness. Glasses of $6 \mathrm{~mm}$ presented a different performance from the others. For load, we observed that the larger the area, the smaller the load applied; however, stress remained constant.

On the other hand, for the temperature simulations the variations of stress and displacement values of panels were obtained due to temperature differences. Table 3 shows visual results for each panel taking into account the average temperatures obtained throughout the year regarding the displacement variable. 
Table 3 - Results from displacements performed by the sottware "Sinulation" for different temperatures on panels used with an image scale of $1: 30 \mathrm{~mm}$.

\begin{tabular}{|c|c|c|c|c|c|}
\hline \multirow[t]{2}{*}{ Code } & \multicolumn{5}{|c|}{$\begin{array}{l}\text { Temperature } \\
\left({ }^{\circ} \mathrm{C}\right)\end{array}$} \\
\hline & -4 & 12.5 & 17.6 & 24 & 40 \\
\hline Al & & & & & \\
\hline$A 2$ & & & & & \\
\hline $\mathrm{A} 3$ & & & & & \\
\hline$A 4$ & & & & & \\
\hline$A 5$ & & & & & \\
\hline A6 & & & & & \\
\hline $\mathrm{B1}$ & & & & & \\
\hline $\mathrm{B} 2$ & & & & & \\
\hline B3 & & & & & \\
\hline B4 & & & & & \\
\hline
\end{tabular}

As the table shows, the displacements occur at the same points, although these values are different for the different temperatures applied.

It was also noticed that for the panels, the regions of displacement differ from one another, that is, none of the displacement regions are equal in comparison to the other panels. It occurs due to different thickness and areas. The graphs of Fig.3 show the maximum stress, at the time for each temperature, taking into account the thickness of the glass analyzed. The maximum stress $\left(65.8 \times 10^{6} \mathrm{~N} / \mathrm{m}^{2}\right)$ supported by the glass used in the simulations is the yield strength of the material.

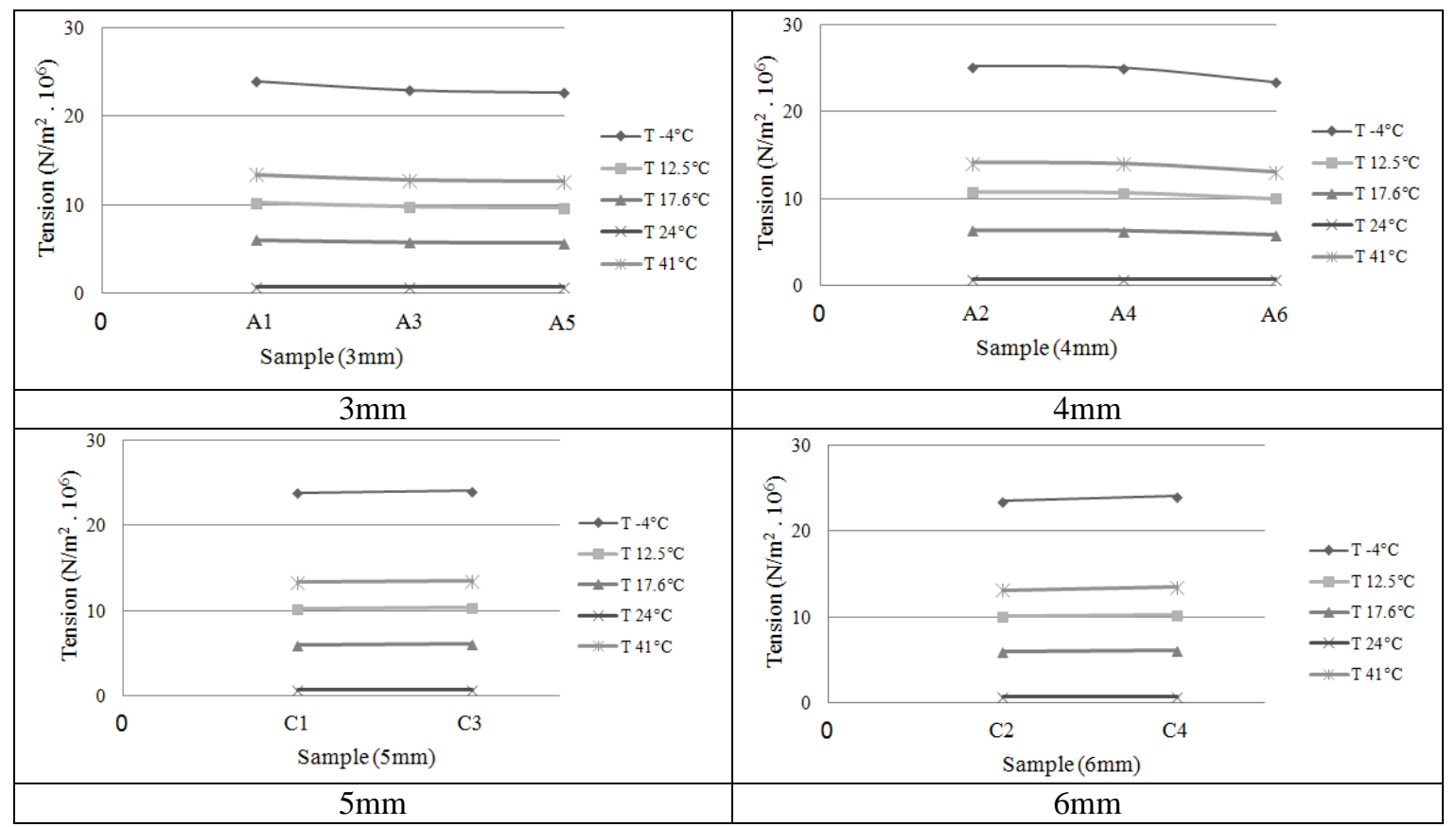

Figure 3 - Load and stress relation in terms of temperature for the different thicknesses. 
The table shows that the temperature of $-4{ }^{\circ} \mathrm{C}$ is the most aggressive to the glass panels since it presents an average stress of $23.81 \times 10^{6} \mathrm{~N} / \mathrm{m}^{2}$ for all glass thicknesses analyzed, on the other hand, the temperature that less compromises is $24{ }^{\circ} \mathrm{C}$ with average stress of $0.70 \times 10^{6} \mathrm{~N} / \mathrm{m}^{2}$ for all glasses. These results showed that in the coldest months the glass is subject to a higher stress in relation to the temperature, although it is important to consider that the maximum temperature for the months hotter than $41^{\circ} \mathrm{C}$, the stress also shows significant intensity index, but lower than the coldest period. For the intermediate temperatures of $12.5^{\circ} \mathrm{C}$ and $17.6{ }^{\circ} \mathrm{C}$, stress related to temperature hardly changed regarding the thickness for the different types of glass analyzed.

\section{CONCLUSION}

The study showed that it is possible to evaluate mechanical behavior and displacement of glass in relation to the simulator of the graphic software Solidworks. Regarding the breakdown stress for less thicker glasses $(3 \mathrm{~mm})$, stress is directly proportional to the area, as for the others $(4,5$, and $6 \mathrm{~mm})$, stress is constant in comparison to the area. The load applied to the glass thickness $(3,4$, and $6 \mathrm{~mm})$ showed results inversely proportional to the area. As for the stress in relation to the temperature it was possible to notice that the temperature of $-4{ }^{\circ} \mathrm{C}$ is the most aggressive on glass panels, although it should be considered that for temperatures higher than $41{ }^{\circ} \mathrm{C}$, stress also presents significant intensity index. In the ending, the graphic software Solidworks Simulation is presented as a great tool for the analysis of this behavior.

\section{REFERENCES}

[1] A. T. Nitsche, M. J. V. dos Santos e E. R. Filho, Um método de transferência de tecnologia baseado no processo de desenvolvimento de produtos, XXIV Encontro Nacional de Engenharia de Produção, Florianópolis (Brasil), 2004, 2823-2830.

[2] T. M. Kiam e N. C. Pereira, Estudo de caso de peça moldada pelo processo de injeção- compressão para termoplásticos utilizando análise computacional. Polímeros: Ciência e Tecnologia, 17 (1), 2007, 16-22.

[3] M. Tufoi, I. Vela, C. Marta, L. Suciu, I. A. Tuta and C. Mituleto, Comparative study of contact stresses and strains at horizontal and vertical continuous casting using conventional and innovative methods of withdrawing profiles, Wseas transactions on applied and Theoretical Mechanics, 5(4), 2010, 252-261.

[4] F. R. Dos Santos, S. C. Ferreira, J. Piaia, Computer aided engineering - CAE, (Universidade do Estado de Santa Catarina, 2004).

[5] Z. Z. Ismail and E. A. Al- Hashmi, Recycling of wast glass a partial replacement for fine aggregate in concrete, Wast Management, 29(2), 2009, 665-669.

[6] M. Akerman, Natureza, estrutura e propriedades do vidro (CETEV- Centro técnico de elaboração do vidro, 2000).

[7] M. Kottek, J. Grieser, C. Beck, B. Rudolf and F. Rubel, World map of the Köppen-Geiger climate classification updated, Meteorologische Zeitschrift, 15(3) , 2006, 259-263.

[8] M. Peel, B. Finlayson and T. McMahon, Updated world map of the Köppen-Geiger climate classification, Hydrology and Earth System Sciences Discussions, 4, 2007, 439-473.

[9] J. Nabialek and J. Koszkul, The influence of input data on the results of injection molding process simulation, $13^{\text {th }}$ International Scientific Conference on Achievements in Mechanical and Materials Engineering, Gliwice-Wisla (Poland), 2005, 455-458.

[10] R.G. Bowman and P.J. Banks, The crucial need for computer modeling of tiling Systems, IV World Congress on Ceramic Tile Quality, Castellón (Spain), 1996, 617-634.

[11] B. Defez, G. Peris-Fajarnés, I. Tortajada Montañana y L. Dunai, Estudio de la evolución y nuevas técnicas de análisis por elementos finitos aplicadas al diseño de pavimentos cerâmicos, Boletin de La Sociedad Española de Cerámica y Vidrio, 48(6), 2009, 273-278. 